Devel opment of a si mple and hi ghl y sensi ti ve mut at i on screeni ng system by enzyne mi smat ch cl eavage wi th opt i mized condi ti ons for st andar d I abor at or i es

\begin{tabular}{|l|l|}
\hline 著者 & Tsuj i Takanor i , N i da Yo \\
\hline $\begin{array}{l}\text { j our nal or } \\
\text { publ i cat i on ti t l e }\end{array}$ & El ect rophor esi s \\
\hline vol une & 29 \\
\hline nunber & 7 \\
\hline page r ange & 1473 1483 \\
\hline year & 2008 O4 01 \\
\hline URL & ht t p: //hdl . handl e. net /2297/9904 \\
\hline
\end{tabular}




\section{Development of a simple and highly sensitive mutation screening system by enzyme mismatch cleavage with optimized conditions for standard laboratories}

Takanori Tsuji and Yo Niida

Department of Pediatrics, Kanazawa University Graduate School of Medical Science, Ishikawa, Japan

Corresponding Author:

Yo Niida, M.D., Ph.D.

Department of Pediatrics, Kanazawa University Graduate School of Medical Science

13-1 Takaramachi, Kanazawa, Ishikawa 920-8641, Japan

Phone: +81 076-265-2313

Fax: +81 076-262-1866

E-mail:niida@ped.m.kanazawa-u.ac.jp

Abbreviations: CMC, chemical mismatch cleavage; DGGE, denaturing gradient gel electrophoresis; DHPLC, denaturing high-performance liquid chromatography; DOVAM-S, detection of virtually all mutation-SSCP; EMC, enzyme mismatch cleavage; FAMA, fluorescence-assisted mismatch analysis; HA, heteroduplex analysis; MALDI, matrix assisted laser desorption/ionization; SSCP, single-trand conformation polymorphism; TGGE, temperature gradient gel electrophoresis; TSC, tuberous sclerosis complex

Keywords: CEL nuclease, enzyme mismatch cleavage, mutation screening, silver staining 
Efficient screening of unknown DNA variations is one of the substantive matters of molecular biology even today. Historically, single-strand conformation polymorphism (SSCP) and heteroduplex analysis (HA) are the most commonly used methods for detecting DNA variations everywhere in the world because of their simplicity. However, the sensitivity of these methods is not satisfactory for screening purpose. Recently, several new PCR based mutation screening methods have been developed, but most of them require special instruments and adjustment of conditions for each DNA sequence to attain the maximum sensitivity, eventually becoming as inconvenient as old methods. Enzyme mismatch cleavage (EMC) is potentially an ideal screening method. With high performance nucleases and once experimental conditions are optimized, it requires only conventional staff and conditions remain the same for each PCR product. In this study we tested four commercially available endonucleases for EMC and optimized the electrophoresis and developing conditions. We prepared 25 known DNA variations consisting of 18 single base substitutions (8 transitions and 10 transversions, including all possible sets of mismatches) and 7 small deletions or insertions. The combination of CEL nuclease, 12\% polyacrylamide gel electrophoresis and rapid silver staining can detect all types of mutations and achieved 100\% sensitivity. 


\section{Introduction}

Determining unknown DNA variations, polymorphisms and mutations, is one of the most time consuming steps for DNA based researches, and is important for detecting the causative gene mutations for the diagnosis of the Mendelian inherited single gene diseases, detecting the somatic mutations of the cancer related genes in the tumor, or list up the single nucleotide polymorphisms to determine the association of candidate genes and clinical phenotypes of multifactorial genetic diseases. The gold standard for detecting DNA variations in the coding region of the gene of interest is to amplify every exon by PCR and perform direct sequencing all of each exon. However, this approach is expensive and unacceptably time consuming, especially when the gene of interest has a large number of exons and/or the researchers needs to screen a large number of samples or genes. Therefore, establishing a simple and effective screening method for unknown DNA variations is one of the most compelling problems of molecular biology even today.

Historically, PCR based gel shift assays, single-strand conformation polymorphism (SSCP) and heteroduplex analysis (HA) were most frequently used for screening of known and unknown mutations. Soon after development, these methods spread all over the world because of their simplicity, i.e. they are easy to perform in standard laboratories without specific equipment or reagents and have high cost performance and high throughput.

The reported sensitivities of SSCP are highly variable and range 50 to $100 \%$ depending on the experimental conditions, including gel running temperature, gel and buffer components, DNA fragment sizes and mutation sites in the fragments [1, 2]. The sensitivity is usually low when using single electrophoresis conditions, about $80 \%$ on an average [3-7], and reaches to $95 \%$ and higher when several different conditions are applied and analyze optimal length fragments [8-11]. DNA fragments sizes profoundly affect the SSCP sensitivity. Hayashi [10] described the sensitivity of SSCP was $97 \%$ when analyzed for 100 to 300 bp segments, though the sensitivity drops to $67 \%$ for 300 to $450 \mathrm{bp}$. Sheffield et al. [5] also reported the sensitivity of SSCP was changed as fragment 
size dependently and maximized at approximately 150 bp. It is obvious that SSCP has DNA fragment size limitation of $<300$ bp to keep the high sensitivity [12]. Because no single condition is universally appropriate for all DNA sequence variations in SSCP analysis, researchers are required to optimize the condition through the several preparatory experiments for each sequence, or run the same samples on several gels with different conditions to obtain the maximum sensitivity.

The reported sensitivity of HA is about $80 \%[13,14]$, and analyzed fragment length are usually similar to SSCP $[15,16]$ or slightly longer $[13,17,18]$. HA has often described to have lower sensitivity for single base substitution compared to insertion or deletion mutations [19-21]. Two modified methods of HA were developed to enhance the migration delay of heteroduplex DNA in the gel by changing the gel component or temperature: denaturing gradient gel electrophoresis (DGGE) and temperature gradient gel electrophoresis (TGGE) [12]. DGGE uses a gel with a gradient of a denaturant, such as urea or hormamide. Heteroduplex DNA is more unstable than homoduplex DNA, so it is denatured at lower concentrations of denaturant and thus migrates in the gel slowly. Consequently, this gel system enhances the separation of heteroduplex to homoduplex DNA. TGGE use the temperature gradient of the gel instead of a denaturant. Similar to DGGE, heteroduplex DNA is denatured at lower temperatures than homoduplex, and this system also enhances the migration delay of heteroduplex DNA. Although these methods potentially have an advantage over HA, they require special equipment for running or making the gel. It could be said that these modifications may increased the net sensitivity but sacrifice the convenience of the original methods. Thus, these modified methods have not become as popular as the original HA.

One clever idea to increase the sensitivity while retaining convenience is to perform SSCP and HA simultaneously in the same gel [22, 23]. Because some mutations can be detected only by SSCP but not by HA, the converse also being true for other mutations, simultaneous detection methods increase the total sensitivity under a single running condition. We have used this SSCP/HA approach to screen unknown mutations for several years; however, the detection sensitivity was not high enough for our expectations (see results). 
The original methods of SSCP and HA have been evolved by several technological improvements. It is now possible that labeling PCR products with fluorescent and adapted SSCP and HA to automated DNA sequencing machines either slab gel electrophoresis [24-28] or capillary electrophoresis (CE) [29-33]. PCR products can be labeled by fluorescent primers [24-26] or fluorescent deoxynucleotides either during PCR [27] or after PCR [34, 35]. CE-SSCP offers the advantages of being automated, high sensitivity allowing the use of fluorescence detection and also achieved high-throughput when adapting multi-capillary system. In addition, several automated CE sequencing instrument can apply to SSCP with some minor adjustments [30, 32, 36, 37]. This would enable laboratories to reduce their capital equipment expenses by using single instrument for both SSCP and sequencing. The sensitivity of CE-SSCP has often been reported to be more than $90 \%$ for fragments with size of 250 bp or smaller [30, 38] and the sensitivity could be increased more than $95 \%$ by using several different temperatures [32, 39]. These progresses of fluorescent labeling and utilizing automated sequencer are also applied to HA [40-42]. Furthermore, Kozlowski et al. [43] showed SSCP/HA combined analysis was achieved by CE platform and demonstrated 100\% sensitivity, whereas SSCP and HA alone provided 90 and 81\% sensitivity, respectively. Tian et al. [42] reported the upper size limit for CE-HA was 200-300 bp. Hence, both SSCP and HA remained a drawback of fragment size limitation even use automated CE platform.

Electrophoresis on microchip is come to fruition and offers the extraordinary rapid analysis system. Tian et al. [33] have demonstrated the ability of microchip SSCP to analyze BRCA1 and BRCA2 common mutations less than $120 \mathrm{~s}$. They also explored the potential of microchip HA and demonstrated high utility, but concluded fragment size upper limitation was 150-260 bp [42]. Microchip electrophoresis seems to offer the best potential in terms of cost effectiveness, rapid analysis, and small requirement of sample volumes. However there is still significant work to be done to confirm the sensitivity and specificity for applying these methods to general mutation screening purpose and still need to overcome the analytical size limitation [12].

Recently, several new high sensitivity and high throughput PCR based mutation screening 
methods other than SSCP and HA have been developed. Some of these require totally new instruments and are consequently not becoming popular because of the initial high cost of these machines. Among them, one of the relatively prevailing technologies is denaturing high-performance liquid chromatography (DHPLC) [44-46]. DHPLC is a type of mobility shift assay that does not involve electrophoresis, but instead detects mutations based on the decreased retention time of the heteroduplex in an HPLC column. Although this new technology achieves high sensitivity, time-consuming optimization of the mutation detection conditions for each DNA sequence is still required to obtain the maximum sensitivity [12].

Another new and rather experimental technology is matrix assisted laser desorption/ionization (MALDI) resequencing [47-50]. Briefly, forward and reverse strands of PCR amplifications are selectively transcribed in vitro, enabled by the incorporation of T7 and SP6 promoter sequences into the 5' ends of the PCR primers. In separate reactions, both transcripts are digested in a controlled manner with RNAses, e.g., specifically cutting after C and U residues, respectively. The fragmentation products are then analyzed by MALDI-time of flight (TOF) mass spectrometry. Mutations become apparent peaks in the spectra in comparison with the wild type. This technology has also achieved high sensitivity but includes cumbersome procedures and cannot be applied to relatively long PCR fragments.

An ideal mutation screening method would require using only conventional equipments and commercially available reagents, a single protocol that can be applied to any DNA sequences and mutation types, the ability to handle long PCR fragments, and would achieve high sensitivity, high throughput and high cost performance. Based on these criteria, even DHPLC and MALDI, which have high sensitivity, are not ideal, because the instruments themselves are too specialized and expensive.

Another approach to developing a mutation screening method is to cleave the mismatch site of the heteroduplex DNA specifically by chemical reagents or single strand specific endonucleases. Historically, chemical mismatch cleavage (CMC) was developed first. Briefly, 
heteroduplex DNA are treated with osmium tetroxide for modifying mismatched thymines, or hydroxylamine for modifying mismatched cytosines. After that, modified heteroduplex DNA are cleaved by piperidine. This approach first utilized radioisotopes [51, 52] and was then modified to use fluorescence and capillary electrophoresis, then called fluorescence-assisted mismatch analysis (FAMA) [53-55]. CMC requires separate treatment of the heteroduplex DNA by osmium tetroxide and hydroxylamine and further requires ethanol precipitation or other purification of the DNA before and after each chemical treatment. Improvements in CMC procedures have been achieved by using endonucleases that specifically react to mismatched sites instead of chemicals to cleave heteroduplex DNA.

This modified method, called enzyme mismatch cleavage (EMC), potentially fulfills the criteria of the ideal mutation screening method described above. That is because this method requires only conventional staff and does not require adjusting of the conditions for each DNA sequence. Heteroduplex DNA is readily cleaved by the enzyme and no need to purify before and after treatment by the enzyme. Furthermore, after the DNA segments are cleaved by the enzyme, they are physically separated on the gel only based on size alone and not by any other parameters. Therefore, there is no need to adjust the gel components or gel running conditions. Thus, if the sensitivity of the enzyme for mismatch cleaving is sufficiently high, EMC may become one of the ideal mutation screening methods. Recently, there are several reports of EMC using different kinds of enzymes [56-63]. Among them CEL nuclease is potentially the most effective enzyme for EMC reported recently [64-70] and is now commercially available as SURVEYOR Nuclease S from Transgenomic (Omaha, NE, USA) [71-73].

In this study, we prepared 25 known DNA variations, consisting of 18 single base substitutions (8 transitions and 10 transversions, including all possible sets of mismatches), 4 small deletions and 3 small insertions, for EMC sensitivity analysis. We tested four commercially available enzymes, T4 endonuclease VII, endonuclease V, T7 endonuclease I and CEL nuclease (SURVEYOR Nuclease S), to compare the sensitivity of EMC with this series of 25 
mutations/polymorphisms. We also compared the results to our SSCP/HA method previously used for mutation screening. In addition, we optimize the gel and gel developing conditions for EMC. Identical samples were separated on both agarose and polyacrylamide gels, and the gels were then developed with either ethidium bromide, SYBR Green I or silver staining to compare the quality of detection.

We found that the CEL enzyme achieved perfect sensitivity (100\%) and was able to detect virtually all types of single base substitutions and any deletion/insertion mutations with the combination of polyacrylamaide gel electrophoresis and optimized rapid silver staining.

\section{Materials and methods}

\subsection{DNA extraction and PCR}

DNA samples were obtained from the patients and their family members in the department of pediatrics, Kanazawa University Hospital. The subjects had known specific gene mutations or polymorphisms determined by previous molecular analysis, and their DNA changes were confirmed by PCR direct sequencing of both forward and reverse sequences using a BigDye Terminator v3.1 cycle sequencing kit and an ABI PRISM 3100 Genetic analyzer (Applied Biosystems, Foster City, CA, USA). The nucleotide changes are summarized in Table 1. The nucleotide number of each gene is according to GenBank accession AF013168, X75621, NM_000487 and NM_004895 for TSC1, TSC2, ARSA and CIAS respectively. DNA samples were also obtained from healthy volunteers as a normal control, and their DNA sequence was confirmed by direct sequencing. After an explanation of this study, written informed consent was obtained from all of the subjects. This study was approved by the ethics committee of the Kanazawa University Graduate School of Medical Science. 
Peripheral blood leukocyte DNA was extracted by a rapid method according to Lahiri et al. $[74,75]$. Extracted DNA samples were diluted by $1 \mathrm{X}$ TE $\left(10 \mathrm{mM}\right.$ Tris- $\mathrm{HCl}, 1 \mathrm{mM} \mathrm{Na} \mathrm{E}_{2} \mathrm{ETA}$ at $\mathrm{pH}$ 7.8) to $0.1 \mu \mathrm{g} / \mu \mathrm{l}$ for use as the PCR template. PCR primers used in this study and corresponding genes are listed in Table 1. All PCR reactions were performed under the same single condition: $0.2 \mu \mathrm{M}$ of each primer, $10 \mathrm{mM}$ Tris- $\mathrm{HCl}(\mathrm{pH} 8.4), 50 \mathrm{mM} \mathrm{KCl}, 2.0 \mathrm{mM} \mathrm{MgCl}_{2}$, and 0.1 unit Taq DNA polymerase (Roche, Grenzacherstrasse, Switzerland) in $5 \mu$ l of reaction volume. Cycle parameters were $94^{\circ} \mathrm{C}$ for $5 \mathrm{~min}$ (initial denaturation), followed by 30 cycles of $95^{\circ} \mathrm{C}$ for 10 sec and $58^{\circ} \mathrm{C}$ for 10 sec, and ending with $72^{\circ} \mathrm{C}$ for 3 min (final extension).

2.2 Heteroduplex formation and enzyme mismatch cleavage

After PCR cycles, heteroduplex DNA were successively produced on a thermal cycler using the following conditions: $85^{\circ} \mathrm{C}$ for $15 \mathrm{~min}$ and $97^{\circ} \mathrm{C}$ for $5 \mathrm{~min}$, for complete denaturation of the PCR products, followed by a reduction in the temperature to $25^{\circ} \mathrm{C}$ by $-1{ }^{\circ} \mathrm{C}$ per min.

We compared four different endonucleases for EMC: T4 endonuclease VII (500U/ul, usb, Cleveland, OH, USA), Endonuclease V (10000U/ml, New England BioLabs, Ipswich, MA, USA), T7 endonuclease I (10000U/ml, New England BioLabs) and CEL enzyme (SURVEYOR Nuclease S, Transgenomic, Omaha, NE, USA).

One $\mu$ l of heteroduplex substrate was incubated with each enzyme and each reaction buffer in a total reaction volume of $5 \mu \mathrm{l}$. The reactions were performed at $42^{\circ} \mathrm{C}$ for SURVEYOR Nuclease $\mathrm{S}$ and at $37^{\circ} \mathrm{C}$ for the other three enzymes. We tested two incubation time for each heteroduplex as short time (20min) and long time (3h). Each enzyme, T4 endonuclease VII, Endonuclease V, T7 endonuclease I, and SURVEYOR Nuclease S, was added to the reactions at 250U, 5U, 5U and $0.25 \mu \mathrm{l}$ for $20 \mathrm{~min}$ digestion and $25 \mathrm{U}, 0.5 \mathrm{U}, 0.5 \mathrm{U}$ and $0.05 \mu \mathrm{l}$ for 3 h digestion, respectively.

The content of each of the reaction buffers is described below. T4 endonuclease VII reaction buffer is $50 \mathrm{mM}$ Tris- $\mathrm{HCl}(\mathrm{pH} 8.0), 10 \mathrm{mM} \mathrm{MgCl}_{2}, 10 \mathrm{mM} \beta-\mathrm{ME}, 0.5 \mu \mathrm{g} / \mu \mathrm{l}$ bovine serum 
albumin (BSA); the Endonuclease $\mathrm{V}$ reaction buffer is $20 \mathrm{mM}$ Tris-acetate $(\mathrm{pH} 7.9), 50 \mathrm{mM}$ potassium acetate, $10 \mathrm{mM}$ magnesium acetate, $1 \mathrm{mM}$ dithiothreitol (DTT); the T7 endonuclease I reactions buffer is $10 \mathrm{mM}$ Tris- $\mathrm{HCl}$ ( $\mathrm{pH} 7.9$ ), $50 \mathrm{mM} \mathrm{NaCl}, 10 \mathrm{mM} \mathrm{MgCl}_{2}, 1 \mathrm{mM}$ dithiothreitol (DTT); and the SURVEYOR Nuclease S reaction buffer is $10 \mathrm{mM}$ Tris- $\mathrm{HCl}(\mathrm{pH} 8.4), 50 \mathrm{mM} \mathrm{KCl}$, 2.0mM $\mathrm{MgCl}_{2}$. The first three enzyme buffers were prepared according to manufactures' instructions, while the SURVEYOR Nuclease S reaction buffer is the same as the PCR reaction buffer.

\subsection{SSCP / HA method}

SSCP and HA can detect in the same gel simultaneously. We modified the methods of Axton et al. for standard slab gel PAGE [23]. In our protocol, after PCR amplification of the specific DNA sequences, $5 \mu$ l of SSCP/HA solution (95\% formamide, $150 \mathrm{mM} \mathrm{NaOH}$, and $0.02 \%$ bromophenol blue (BPB)) was added to $5 \mu$ l of the PCR reaction solution. The mixture was heated with the thermal cycler at $99^{\circ} \mathrm{C}$ for $5 \mathrm{~min}$ and then quickly cooled on ice for $15 \mathrm{~min}$. All samples were loaded on a SSCP/HA gel (12\% polyacrylamide (Acr/Bis = 49:1, 8\% glycerol) $)$ and run at 15V/cm for $2 \mathrm{~h}$ at room temperature in $1 \mathrm{X}$ TBE (100 mM Tris-HCl (pH 8.0), 83mM boric acid, and $1 \mathrm{mM} \mathrm{Na} \mathrm{N}_{2}$ EDTA). The gel was developed with an optimized silver staining procedure described below.

Using this protocol, approximately half of the PCR products assume a single stranded conformation while the rest are double stranded DNA in hetero- or homoduplex form. Because double stranded DNA runs faster than single stranded DNA, the lower part of the gel showed HA, and at the same time the upper part of the gel showed SSCP analysis (Figure 1).

\subsection{Electrophoresis and developing the gel}


To compare band separation ability and developing sensitivity, we performed four identical mismatch cleavage reactions, each with a five $\mu \mathrm{l}$ reaction volume, with CEL enzyme for all 25 DNA variations. Two of them were mixed with one $\mu$ l of gel loading buffer ( $50 \%$ glycerol, $10 \mathrm{mM}$ Tris- $\mathrm{HCl}$ (pH 8.0), 0.1\% SDS, 3mM EDTA, 0.02\% BPB) and run on the 3\% agarose gels (NuSieve 3:1, Cambrex Bio Science, Rockland, ME, USA) for $30 \mathrm{~min}$ at $100 \mathrm{~V}$ in $1 \mathrm{X}$ TBE. The remaining two samples were mixed with $5 \mu$ l of glycerol loading buffer (50\% glycerol, 5mM Tris-HCl (pH 7.8), 0.5mM EDTA, $0.02 \%$ BPB) and run on 12\% polyacrylamide gels (Acr/Bis = 19:1, 8\% glycerol; $200 \mathrm{~mm} \times 105 \mathrm{~mm} \times 1 \mathrm{~mm}$, with 37 wells) for $90 \mathrm{~min}$ at $15 \mathrm{~V} / \mathrm{cm}$ in $1 \mathrm{X}$ TBE. Therefore, a total of four gels were run separately. The agarose gels were then developed with ethidium bromide or SYBR Green I (Invitrogen, Carlsbad, CA, USA), and the polyacrylamide gels were developed with SYBR Green I or silver staining for comparison. After electrophoresis, agarose gels were transferred to a container with $1 \mathrm{X}$ TBE and ethidium bromide (to $1 \mu \mathrm{g} / \mathrm{ml}$ ) or SYBR Green I (to a 1:10000 dilution) were added. The gel was stained with adequate agitation for $20 \mathrm{~min}$ at room temperature, and the DNA bands were then detected under the UV transilluminator. For SYBR Green I, a SYBR Green/Gold photographic filter (Invitrogen) was used to take pictures. One polyacrylamide gel was stained with SYBR Green I and detected in the same way. The remaining polyacrylamide gel was developed by silver staining. We used an optimized silver staining method described by Ji et al. [76], with the following modifications. After electrophoresis, the gel was rinsed in deionized water briefly and then incubated in $0.1 \%$ AgNO3 (w/v) for $5 \mathrm{~min}$ at room temperature with gentle agitation. The AgNO3 solution was reclaimed, and the gel was quickly rinsed with deionized water three times. The gel was then incubated with $0.04 \% \mathrm{Na}_{2} \mathrm{CO}_{3}(\mathrm{w} / \mathrm{v}), 0.5 \% \mathrm{NaOH}(\mathrm{w} / \mathrm{v})$, and $0.2 \mathrm{ml} 37 \%$ $\mathrm{HCOH}$ per $100 \mathrm{ml}$ solution was added to for 3 to $5 \mathrm{~min}$ at room temperature to develop the gel. After developing a sufficient intensity of the bands, the gel was rinsed with deionized water briefly, and the reaction was stopped with $1 \%$ acetic acid. All of these four gels were compared with regard to sensitivity and quality for each sample (Figure 2).

According to the results of this comparison, all subsequent T4 endonuclease VII, 
endonuclease V and T7 endonuclease I EMC samples were run on 12\% polyacrylamide gels and developed by silver staining. Also, all SSCP/HA gels were developed by silver staining.

\section{Results}

Under our conditions, we observed no mismatch cleavage by T4 endonuclease VII and endonuclease $\mathrm{V}$ in any type of mutation/polymorphism prepared for this study (Figure 3). We re-tested with a 10 fold higher concentration of these enzymes with $10 \mu$ l and $25 \mu$ l of reaction volume for digesting one $\mu \mathrm{l}$ of heteroduplex DNA and increased the incubation time to 24h; however, again no cleavage was confirmed. T7 endonuclease I detected several mutations/polymorphisms, and the CEL enzyme detected all of the 25 DNA variations. For these two enzymes, both 20min digestion with high titer enzyme and 3h digestion with low titer enzyme were equally effective, and no difference in the results was observed. When using low titer enzyme, nonspecific or over digestions were not observed until at least 24h. Results of detection for each DNA variation by each method are listed in Table 2, and overall sensitivities are summarized in Table 3.

In SSCP / HA screening, more single base substitutions were detected by SSCP than HA, and more insertion/deletion mutations were detected by HA than SSCP. SSCP and HA complement each other in the detection of DNA variations, and the use of them together increases the sensitivity compared to each method alone. However, the total sensitivity of SSCP / HA method remained at 52\% (Table 3). T7 endonuclease I can detect all insertion/deletion mutations and 61\% of single base substitutions (63\% of transitions and $60 \%$ of transversions) with a total sensitivity of $72 \%$. Under our conditions, the CEL enzyme had $100 \%$ total sensitivity and was able to detect all single base substitutions and insertion/deletion mutations of the 25 different DNA variations. Apparently, CEL mediated EMC is superior to T7 endonuclease I or SSCP/HA analysis (Figure 1, 4).

Comparing T7 endonuclease I to CEL nuclease reveals that CEL can detect more single 
base substitutions than T7 endonuclease I. CEL can cleave all transitions and transversions which can not be cleaved by T7 endonuclease I. On the other hand, insertion/deletion mutations seemed to be more clearly cleaved by T7 endonuclease I than CEL nuclease (Figure 4). However, both enzymes cleaved all insertion/deletion mutations, and their detection sensitivity was not different.

Cleaved DNA segments were more clearly separated on polyacrylamide gel compared with agarose gel. Also, some cleaved bands, especially those representing single base substitutions, were very faint and difficult to discern in agarose gel. In agarose gel, SYBR Green I staining did not increase the detection sensitivity compared to ethidium bromide staining. Silver staining and SYBR Green I staining of polyacrylamide gels was better than agarose gels, and silver staining most surely and easily detected the cleaved band (Figure 2).

\section{Discussion}

Detecting unknown DNA variations is one of the key steps in many areas of genetic research. To date, many mutation screening methods have been invented, but no one method satisfies both simplicity and high sensitivity for screening purposes. Recently, totally new equipment, such as CE-SSCP/HA, DHPLC and MALDI, has been introduced to this field. Methods utilizing this equipment demonstrate high sensitivity and high throughput, but none have become widely used because of the high cost of these machines. The current tendency that a few heavily equipped laboratories with expensive specialized equipment create a monopoly of high throughput mutation analysis is undesirable for the further progress of molecular biology. Since virtually every researcher studying DNA needs to detect mutations or polymorphisms in some steps of their work, there is an increasing need for the development of easy to use, highly sensitive and high cost performance methods for the massive majority of scientists working in laboratories with standard equipment. 
Historically, SSCP and HA lead in this field, but generational change is at the gate. Actually, these methods have several disadvantages. HA has a relatively low sensitivity for single base substitutions, and both HA and SSCP have size limit on the fragments that can be analyzed. In fact, current studies show that SSCP/HA analysis detects only 52\% of DNA variations. HD and SSCP detect only two and five single base substitutions, respectively. Previous data from our group showed a nearly $60 \%$ of mutation detecting ability for screening the mutation unknown patient populations of tuberous sclerosis complex (TSC) using the same methods $[77,78]$. It seems that the present study included relatively large size PCR products which reduced SSCP/HA sensitivity.

Enzyme mismatch cleavage (EMC) is one of the breakthroughs of mutation screening strategies. EMC may actually become an ideal method with the recently discovered neutral $\mathrm{pH}$ DNA endonucleases isolated from celery, the CEL nuclease family. There are several reports that EMC using CEL I nuclease demonstrates a very high sensitivity [70, 73]. According to Qiu et al. [71], the SURVEYOR Nuclease S corresponds to CEL II nuclease, a putative isozyme of CEL I nuclease [65]. EMC can be applied to longer PCR fragments compared to SSCP and HA [69, 70]. Qiu et al. analyzed 2.95-kb heteroduplex DNA by Surveyor nuclease [71]. In general, SSCP is thought to be most sensitive in detecting mutations when the fragment size is shorter than 200bp, and the size limit for high sensitivity is 300bp [1], even using CE-SSCP [12]. This size limitation produces a cost and effort disadvantage when analyzing long exons, i.e. more PCR primers and more PCR reactions are required. To overcome the size limitation, a new method combining dideoxyfingerprinting and SSCP, named “detection of virtually all mutation-SSCP” (DOVAM-S), was developed [79-81]. However, DOVAM-S requires several gel running conditions to attain detection of virtually all mutations, making it relatively inconvenient as well. On the other hand, CEL mediated EMC can be applied to long segments of more than $1 \mathrm{~kb}$. Because this size exceeds the length of limitation of standard direct sequencing, it could be said that EMC extends the analytical length enough for PCR based mutation screening.

We tested four commercially available endonucleases for EMC. Among them, we detected 
no mismatch cleavage by T4 endonuclease VII and endonuclease V. In our protocol, PCR products are readily convert to heteroduplex and cleaved by enzyme without any purification. Therefore, purification of heteroduplex DNA may be necessary before cleaving by T4 endonuclease VII and endonuclease V. Nonetheless, a purification step is not desireable for a simple procedure, and we do not want to use these enzymes for EMC. CEL nuclease and T7 endonuclease I showed clear mismatch incision without any purification steps. In terms of overall sensitivity, CEL nuclease is clearly better than T7 endonuclease I, mainly for the better sensitivity to single base substitutions.

There are two major groups of single base substitutions, transitions and transversions. Transitions is defined as one of the purines (A or $G$ ) is converted to the other purine ( $G$ or $A$ ) or one of the pyrimidines ( $\mathrm{T}$ or $\mathrm{C}$ ) is converted to the other pyrimidine ( $\mathrm{C}$ or $\mathrm{T}$ ). However, in fact, because purines are paired to pyrimidines in the double-strand DNA, when interchange of purines are happened in the one strand of the DNA, at the same time in the complementary strand, interchange of pyrimidines are occurred, and vice versa. Therfore, ignore the sense and anitisense direction of double stranded DNA and avoid duplication, transition can be simplified to the interchange of A:T base pair and G:C base pair in one allele of the gene. Then, possible mismatches of the heteroduplex DNA formed with wild type allele and substituted allele are A/C and G/T. Another type of single base substitution is the transversion. Transversion is defined as a purine is converted to a pyrimidine or vice versa. In this situation, one of the purines (A or $G$ ) is converted to a pyrimidine ( $\mathrm{C}$ or $\mathrm{T}$ ) in one strand of the DNA, and in the complementary strand, one of the corresponding pyrimidines ( $\mathrm{T}$ or $\mathrm{C}$ ) is converted to a purine ( $\mathrm{G}$ or $\mathrm{A}$ ) simultaneously. Thus, the possible conversion set of base pairs is, ignore the DNA strand direction and after simplification, A:T to C:G, A:T to T:A and G:C to C:G (note G:C to T:A is equivalent to A:T to C:G). Accordingly, the possible mismatches formed in the heteroduplex DNA are A/G, C/T, A/A, T/T, C/C, and G/G. In both transition and transversion, one single base substitution causes a pair of heteroduplexes. In summary, four possible single base substitutions, one transition $A$ to $G$ ( $T$ to $C$ in the complementally strand) and three transversions A to C (T to $G$ ), A to T (T to A) and G to C (C to G), 
cause four possible pairs of heteroduplexes; A/C and G/T, A/G and C/T, A/A and T/T, and C/C and G/G. (see also Table 2). CEL I nuclease can cleave all of these mismatches. However, CEL I does demonstrate some substrate preference, as C/C was cleaved the most, T/T was cleaved least, and other mismatches were cleaved intermediately [64]. On the other hand, T7 endonuclease I is also said to cleave all type of mismatches; however, its properties have not been well studied [58, 62]. In our mutation/polymorphism collection, CEL nuclease could cleave all 18 single base substitutions, including three transitions and four transversions which were not cleaved by T7 endonuclease I. These 18 single base substitutions included all types of base pair changes and mismatches described above. These results proved that CEL nuclease based EMC can be applied to detect any kind of single base substitutions.

Interestingly, there was some tendency for T7 endonuclease I to cleave deletion/insertion heteroduplex more readily than CEL nuclease (Figure 4). These results may reflect a difference in the nature of each endonuclease. Technically, CEL nuclease also cleaved deletions/insertions mutations very well, and heteroduplex DNA formed by large deletions/insertions of more than 10bp could migrate slowly in polyacrlylamide gel thereby allowing for HA and assist in mutation detection (I3 in Figure 4). Therefore, this type of cleavage limitation does not truly affect the total sensitivity of CEL mediated EMC when using a polyacrylamide gel.

In the separation and developing of the cleaved DNA fragments, some cleaved band were very faint or not well separated and thus difficult to detect in agarose gel. This could not be overcome by staining the agarose gel with SYBR Green I instead of ethidium bromide. SYBR Green I stains DNA bands more brightly than ethidum bromide, but it usually does not help to pick out the shorter bands from the large majority of un-cleaved bands. This is because band separation is poor in agarose gels in general. Fragment separation in polyacrylamide gel is better than agarose gel, and silver staining of polyacrylamide gels was diplayed higher sensitivity than SYBR Green I staining. Furthermore, silver staining has other advantages over SYBR Green I staining. Silver stained gels can be kept for long time in nylon packs at $4^{\circ} \mathrm{C}$, and the cleaved band is always visible 
to the naked eye with ambient light. According to Beidler et al. [82] silver staining of double-stranded DNA is at least 100 times as sensitive as fluorescence staining with ethidium bromide. In principle, the optical density of silver stained double stranded DNA in a polyacrylamide gel is proportional to DNA amount before the band density is saturated [82, 83, 86]. However, Goldman et al. [83] found the greater staining of smaller DNA fragments relative to larger ones by silver staining. The increasing rate of the band intensity per DNA increment is similar for pieces of DNA larger than $300 \mathrm{bp}$, but is greater for fragments of smaller size. Additionally, the optical density of larger DNA fragments saturate faster than smaller fragments [83], as a result, smaller fragments can be stained appropriately without burning out of larger bands. Based on this property, silver staining can stains smaller bands more effectively or stains more equally throughout the different size of the fragments comparing to ethidium bromide staining [82, 84, 85]. This characteristic feature of silver staining is perfectly fit to EMC. It makes easy to detect the small size fragments produced by mismatch cleavage and also make easy to distinguish the cleaved bands not so mach shorter than the un-cleaved wild type fragments. Many people think silver staining is an inconvenient, complicated and time consuming method for detection, but the optimized silver staining methods by Ji et al. [76]. are easy and extraordinarily convenient, requiring the use of few reagents and less than $10 \mathrm{~min}$ to complete. Thus, we recommend polyacrlamide gel electrophoresis and silver staining as a routine protocol for mutation detection systems.

EMC showed very high performance with a standard slab gel system, but this method can also be applied to new technologies, such as capillary electrophoresis with fluorescence or semiautomatic high throughput machines like the WAVE system (Transgenomic, Omaha, NE, USA). Thus, a CEL nuclease based EMC system could be widely used in any type of laboratory and may spread worldwide as the next trend in molecular genetics.

In this study, using only conventional equipment belonging to a basic laboratory and commercially available reagents and enzyme, we showed that CEL nuclease mediated EMC can detect any kind of DNA variation with very high sensitivity, no need to adjust the experimental 
protocol to each DNA sequence, applicable to long PCR fragments, and high cost performance (less than 15 cents per sample when using low titer enzyme). Also, this EMC method is possible to apply to fluorescence automated sequencer [64, 65, 87] and CE platform [73] according to your laboratory equipments. We have established an ideal mutation screening system which is available to most any researcher. 


\section{Acknowledgment}

This work was supported by a Grant-in-Aid for Scientific Research from the Ministry of

Education, Culture, Sports, Science and Technology of Japan, and a grant from the Ministry of Health, Labor, and Welfare of Japan, Tokyo. 


\section{References}

[1] Hayashi, K., Yandell, D., Hum Mutat 1993, 2, 338-346.

[2] Liu, Q., Sommer, S., PCR Methods Appl 1994, 4, 97-108.

[3] Vidal-Puig, A., Moller, D., Biotechniques 1994, 17, 490-492, 494, 496.

[4] Ravnik-Glavac, M., Glavac, D., Dean, M., Hum Mol Genet 1994, 3, 801-807.

[5] Sheffield, V., Beck, J., Kwitek, A., Sandstrom, D., Stone, E., Genomics 1993, 16, 325-332.

[6] Gerhardus, A., Schleberger, H., Schlegelberger, B., Gadzicki, D., Eur J Hum Genet 2007, 15, 619-627.

[7] Andrulis, I., Anton-Culver, H., Beck, J., Bove, B., et al., Hum Mutat 2002, 20, 65-73.

[8] Jordanova, A., Kalaydjieva, L., Savov, A., Claustres, M., et al., Hum Mutat 1997, 10, 65-70.

[9] Eng, C., Brody, L., Wagner, T., Devilee, P., et al., J Med Genet 2001, 38, 824-833.

[10] Hayashi, K., PCR Methods Appl 1991, 1, 34-38.

[11] Gross, E., Arnold, N., Goette, J., Schwarz-Boeger, U., Kiechle, M., Hum Genet 1999, 105, $72-78$

[12] Hestekin, C., Barron, A., Electrophoresis 2006, 27, 3805-3815.

[13] Ganguly, A., Rock, M., Prockop, D., Proc Natl Acad Sci U S A 1993, 90, 10325-10329.

[14] Perry, D., Carrell, R., J Clin Pathol 1992, 45, 158-160.

[15] Gayther, S., Harrington, P., Russell, P., Kharkevich, G., et al., Am J Hum Genet 1996, 58, 451-456.

[16] Maynard, J., Upadhyaya, M., Biotechniques 1998, 25, 648-651.

[17] Balogh, K., Patócs, A., Majnik, J., Rácz, K., Hunyady, L., Mol Genet Metab 2004, 83, 74-81.

[18] Boyd, M., Lanyon, W., Connor, J., Hum Mutat 1993, 2, 127-130.

[19] Lohmann, D., Brandt, B., Höpping, W., Passarge, E., Horsthemke, B., Am J Hum Genet 1996, 58, 940-949.

[20] Abernathy, C., Rasmussen, S., Stalker, H., Zori, R., et al., Hum Mutat 1997, 9, 548-554. 
[21] Wikman, F., Katballe, N., Christensen, M., Laurberg, S., Orntoft, T., Genet Test 2000, 4, $15-21$.

[22] Liechti-Gallati, S., Schneider, V., Neeser, D., Kraemer, R., Eur J Hum Genet 1999, 7, 590-598.

[23] Axton, R., Hanson, I., Love, J., Seawright, A., et al., Mol Cell Probes 1997, 11, 287-292.

[24] Makino, R., Yazyu, H., Kishimoto, Y., Sekiya, T., Hayashi, K., PCR Methods Appl 1992, 2, $10-13$.

[25] Ellison, J., Dean, M., Goldman, D., Biotechniques 1993, 15, 684-691.

[26] Iwahana, H., Yoshimoto, K., Mizusawa, N., Kudo, E., Itakura, M., Biotechniques 1994, 16, 296-297, 300-295.

[27] Iwahana, H., Fujimura, M., Takahashi, Y., Iwabuchi, T., et al., Biotechniques 1996, 21, 510-514, 516-519.

[28] Dobson-Stone, C., Cox, R., Lonie, L., Southam, L., et al., Eur J Hum Genet 2000, 8, 24-32.

[29] Inazuka, M., Wenz, H., Sakabe, M., Tahira, T., Hayashi, K., Genome Res 1997, 7, 1094-1103.

[30] Atha, D., Wenz, H., Morehead, H., Tian, J., O'Connell, C., Electrophoresis 1998, 19, 172-179.

[31] Ren, J., Ueland, P., Hum Mutat 1999, 13, 458-463.

[32] Larsen, L., Christiansen, M., Vuust, J., Andersen, P., Hum Mutat 1999, 13, 318-327.

[33] Tian, H., Jaquins-Gerstl, A., Munro, N., Trucco, M., et al., Genomics 2000, 63, 25-34.

[34] Iwahana, H., Adzuma, K., Takahashi, Y., Katashima, R., et al., PCR Methods Appl 1995, 4, 275-282.

[35] Inazuka, M., Tahira, T., Hayashi, K., Genome Res 1996, 6, 551-557.

[36] Holmila, R., Husgafvel-Pursiainen, K., Cancer Detect Prev 2006, 30, 1-6.

[37] Bosserhoff, A., Seegers, S., Hellerbrand, C., Schölmerich, J., Büttner, R., Biotechniques 1999, 26, 1106-1110.

[38] Mogensen, J., Bahl, A., Kubo, T., Elanko, N. et al., J. Med. Genet. 2006, 40, e59.

[39] Andersen, P., Jespersgaard, C., Vuust, J., Christiansen, M., Larsen, L., Hum Mutat 2003, 21, 116-122. 
[40] Ganguly, T., Dhulipala, R., Godmilow, L., Ganguly, A., Hum Genet 1998, 102, 549-556.

[41] Blesa, J., Hernández-Yago, J., Biotechniques 2000, 28, 1019-1025.

[42] Tian, H., Brody, L., Landers, J., Genome Res 2000, 10, 1403-1413.

[43] Kozlowski, P., Krzyzosiak, W., Nucleic Acids Res 2001, 29, E71.

[44] Frueh, F., Noyer-Weidner, M., Clin Chem Lab Med 2003, 41, 452-461.

[45] Kosaki, K., Udaka, T., Okuyama, T., Mol Genet Metab 2005, 86, 117-123.

[46] Xiao, W., Oefner, P., Hum Mutat 2001, 17, 439-474.

[47] Garvin, A., Parker, K., Haff, L., Nat Biotechnol 2000, 18, 95-97.

[48] Koren-Michowitz, M., Shimoni, A., Vivante, A., Trakhtenbrot, L., et al., Leuk Res 2007.

[49] Ragoussis, J., Elvidge, G., Kaur, K., Colella, S., PLoS Genet 2006, 2, e100.

[50] Mauger, F., Bauer, K., Calloway, C., Semhoun, J., et al., Nucleic Acids Res 2007, 35, e62.

[51] Grompe, M., Muzny, D., Caskey, C., Proc Natl Acad Sci U S A 1989, 86, 5888-5892.

[52] Cotton, R., Rodrigues, N., Campbell, R., Proc Natl Acad Sci U S A 1988, 85, 4397-4401.

[53] Ren, J., Ulvik, A., Refsum, H., Ueland, P., Clin Chem 1998, 44, 2108-2114.

[54] Germain, D., Biasotto, M., Tosi, M., Meo, T., et al., Hum Genet 1996, 98, 719-726.

[55] De Galitiis, F., Cannita, K., Tessitore, A., Martella, F., et al., Ann Oncol 2006, 17 Suppl 7, vii78-vii83.

[56] Brown, J., Brown, T., Fox, K., Biochem J 2003, 371, 697-708.

[57] Feng, H., Klutz, A., Cao, W., Biochemistry 2005, 44, 675-683.

[58] Babon, J., McKenzie, M., Cotton, R., Mol Biotechnol 2003, 23, 73-81.

[59] Babon, J., Youil, R., Cotton, R., Nucleic Acids Res 1995, 23, 5082-5084.

[60] Babon, J., McKenzie, M., Cotton, R., Electrophoresis 1999, 20, 1162-1170.

[61] Yuan, B., Thomas, J., von Kodolitsch, Y., Pyeritz, R., Hum Mutat 1999, 14, 440-446.

[62] Mean, R., Pierides, A., Deltas, C., Koptides, M., Biotechniques 2004, 36, 758-760.

[63] Gao, H., Huang, J., Barany, F., Cao, W., Nucleic Acids Res 2007, 35, e2.

[64] Oleykowski, C., Bronson Mullins, C., Godwin, A., Yeung, A., Nucleic Acids Res 1998, 26, 
4597-4602.

[65] Yang, B., Wen, X., Kodali, N., Oleykowski, C., et al., Biochemistry 2000, 39, 3533-3541.

[66] Colbert, T., Till, B., Tompa, R., Reynolds, S., et al., Plant Physiol 2001, 126, 480-484.

[67] Till, B., Reynolds, S., Greene, E., Codomo, C., et al., Genome Res 2003, 13, 524-530.

[68] Perry, J., Wang, T., Welham, T., Gardner, S., et al., Plant Physiol 2003, 131, 866-871.

[69] Sokurenko, E., Tchesnokova, V., Yeung, A., Oleykowski, C., et al., Nucleic Acids Res 2001, 29, E111.

[70] Greber, B., Tandara, H., Lehrach, H., Himmelbauer, H., Hum Mutat 2005, 25, 483-490.

[71] Qiu, P., Shandilya, H., D'Alessio, J., O'Connor, K., et al., Biotechniques 2004, 36, 702-707.

[72] Till, B., Burtner, C., Comai, L., Henikoff, S., Nucleic Acids Res 2004, 32, 2632-2641.

[73] Yeung, A., Hattangadi, D., Blakesley, L., Nicolas, E., Biotechniques 2005, 38, 749-758.

[74] Lahiri, D., Bye, S., Nurnberger, J. J., Hodes, M., Crisp, M., J Biochem Biophys Methods 1992, 25, 193-205.

[75] Lahiri, D., Schnabel, B., Biochem Genet 1993, 31, 321-328.

[76] Ji, Y., Qu, C., Cao, B., Electrophoresis 2007, 28, 1173-1175.

[77] Beauchamp, R., Banwell, A., McNamara, P., Jacobsen, M., et al., Hum Mutat 1998, 12, 408-416.

[78] Niida, Y., Lawrence-Smith, N., Banwell, A., Hammer, E., et al., Hum Mutat 1999, 14, 412-422.

[79] Liu, Q., Feng, J., Buzin, C., Wen, C., et al., Biotechniques 1999, 26, 932, 936-938, 940-932.

[80] Buzin, C., Wen, C., Nguyen, V., Nozari, G., et al., Biotechniques 2000, 28, 746-750, 752-743.

[81] Buzin, C., Gatti, R., Nguyen, V., Wen, C., et al., Hum Mutat 2003, 21, 123-131.

[82] Beidler, J., Hilliard, P., Rill, R., Anal Biochem 1982, 126, 374-380.

[83] Goldman, D., Merril, C., Electrophoresis 1982, 3, 24-26.

[84] Boulikas, T., Hancock, R., J Biochem Biophys Methods 1981, 5, 219-228.

[85] Qu, L., Li, X., Wu, G., Yang, N., Electrophoresis 2005, 26, 99-101.

[86] Merril, C., Pratt, M., Anal Biochem 1986, 156, 96-110. 
[87] Kulinski, J., Besack, D., Oleykowski, C., Godwin, A., et al., Biotechniques 2000, 29, 44-48. 
Table 1. Nucleotide changes and PCR primers

\begin{tabular}{|c|c|c|c|c|c|}
\hline Index & Gene & $\mathrm{Ex} / \mathrm{In}$ & Nucleotide change & Forward Primer & Reverse Primer \\
\hline TS1 & TSC1 & In 3 & IVS3+15A $>$ G & gaaccttcagaacctgtagc & cagcaggattctagtggctc \\
\hline TS2 & TSC1 & In 16 & IVS16+1G $>A$ & gaccacaaggaagtgatctaac & aaccatgtgggctggatttg \\
\hline TS3 & TSC1 & In 19 & IVS19+51A/G & gaaagtagagccgttgagct & ccatgacacagacactcaagt \\
\hline TS4 & TSC2 & In 15 & IVS15-15G>A & tgctgactcagaaccatgag & ctggtggacgctagccatg \\
\hline TS5 & TSC2 & Ex 27 & $3273 \mathrm{C}>\mathrm{T}, \mathrm{G} 1091 \mathrm{G}$ & caacttcacggctgtccсg & tgtcgaggctggcaggcg \\
\hline TS6 & TSC2 & Ex 40 & 5228G $>$ A, R1743Q & tggccaagatcgtgtctgac & gacaggcaataccgtccaag \\
\hline TS7 & ARSA & Ex 6 & 1424A>G, N350S & cttgatggcgaactgagtga & aggtcaaagccatccaagg \\
\hline TS8 & CIAS & Ex 3 & $1478 \mathrm{~A}>\mathrm{G}, \mathrm{A} 242 \mathrm{~A}$ & aggagctgcaccttccatt & agtgcagagcggtcctatgt \\
\hline TV1 & TSC2 & In 39 & IVS39-9C>A & tggccaagatcgtgtctgac & gacaggcaataccgtccaag \\
\hline TV2 & CIAS & In 8 & IVS8+44A>C & cagcatacaaggctgcttga & caggcccaacctaatcttga \\
\hline TV3 & TSC2 & Ex 12 & $1348 \mathrm{G}>\mathrm{T}, \mathrm{E} 450 \mathrm{X}$ & caacaccggctcttcttttg & tgccaggcaaggctacagag \\
\hline TV4 & TSC2 & In 28 & IVS28+2T $>$ G & gactaagtcaccctgtgcgt & ccagcagcaactgagggag \\
\hline TV5 & ARSA & In 7 & IVS7+20C $>G$ & gcggactggaaagtacaagg & tgagcagtcagagagctgga \\
\hline TV6 & TSC2 & Ex 36 & 4713C $>$ G, Y1571X & ttgtctgcctcagggatcag & ggggtagcaggactggatg \\
\hline TV7 & TSC1 & Ex 19 & 2646G>C, E809E & gaaagtagagccgttgagct & ccatgacacagacactcaagt \\
\hline TV8 & TSC2 & Ex 16 & $1796 \mathrm{~A}>\mathrm{T}, \mathrm{K} 599 \mathrm{M}$ & gtgctgtcttaggactgcg & gtctctgcagcttccaggaa \\
\hline TV9 & TSC2 & Ex 39 & $5110 \mathrm{~T}>\mathrm{A}, \mathrm{S} 1704 \mathrm{~T}$ & gctgcagtgtggcgccaaga & gagctcactatcaggtggca \\
\hline TV10 & TSC1 & Ex 15 & 2104T>A, L628X & attgccaaagacagcccatc & aggtgggagtgtgaagaatg \\
\hline D1 & $A R S A$ & In 3 & IVS3-3delC & gtgacccctacccagtgcta & agatgaccagcgtctcttcaa \\
\hline $\mathrm{D} 2$ & TSC1 & In 15 & IVS15+67-68delAG & attgccaaagacagcccatc & aggtgggagtgtgaagaatg \\
\hline D3 & TSC2 & Ex 30 & 3620-3624delGCTGG & agatgggtaaggggaggtac & ggagcagagcccgtgccaa \\
\hline D4 & TSC2 & Ex 40 & 5238-5255del (18bp del) & tggccaagatcgtgtctgac & gacaggcaataccgtccaag \\
\hline I1 & ARSA & Ex 2 & 1190-1191insC & gtatcggaaagagcctgctg & cctacctggtcgtgggagta \\
\hline $\mathrm{I} 2$ & TSC2 & Ex 10 & 980-981insAT & gcagctctgaccetgtgtgc & tggccgagcctgcctgtct \\
\hline I3 & TSC2 & Ex 33 & $\begin{array}{l}\text { 4159-4160insCCTGAGCA } \\
\text { AGTCCAGCT (17bp ins) }\end{array}$ & ctgacaggggttctctttgg & tccagggtccctgactgtga \\
\hline
\end{tabular}

Nucleotide number of each gene is according to GenBank accession AF013168, X75621, NM_000487 and NM_004895 for TSC1, TSC2, ARSA and CIAS respectively. 
Table 2. Mismatch types and results of enzymatic cleavage

\begin{tabular}{|c|c|c|c|c|c|c|c|}
\hline Index & $\begin{array}{l}\text { Nucleotide } \\
\text { change }\end{array}$ & mismatch & Size (bp) & $\begin{array}{l}\text { Mut/Poly } \\
\text { position }\end{array}$ & SSCP/HA & T7EI & CEL \\
\hline \multicolumn{8}{|c|}{ Single base substitution } \\
\hline \multicolumn{8}{|c|}{ Transition } \\
\hline TS1 & $A>G$ & $\mathrm{G} / \mathrm{T}, \mathrm{A} / \mathrm{C}$ & 241 & 180 & $\mathrm{~N} / \mathrm{N}$ & $\mathrm{Y}$ & $\mathrm{Y}$ \\
\hline TS2 & $\mathrm{G}>\mathrm{A}$ & $\mathrm{A} / \mathrm{C}, \mathrm{G} / \mathrm{T}$ & 185 & 145 & $\mathrm{~N} / \mathrm{N}$ & $\mathrm{Y}$ & $\mathrm{Y}$ \\
\hline TS3 & $A>G$ & $\mathrm{G} / \mathrm{T}, \mathrm{A} / \mathrm{C}$ & 332 & 278 & $\mathrm{~N} / \mathrm{N}$ & $\mathrm{Y}$ & $\mathrm{Y}$ \\
\hline TS4 & $\mathrm{G}>\mathrm{A}$ & $\mathrm{A} / \mathrm{C}, \mathrm{G} / \mathrm{T}$ & 276 & 48 & $\mathrm{~N} / \mathrm{N}$ & $\mathrm{N}$ & $\mathrm{Y}$ \\
\hline TS5 & $\mathrm{C}>\mathrm{T}$ & $\mathrm{T} / \mathrm{G}, \mathrm{C} / \mathrm{A}$ & 298 & 142 & $\mathrm{~N} / \mathrm{Y}$ & $\mathrm{N}$ & $\mathrm{Y}$ \\
\hline TS6 & $\mathrm{G}>\mathrm{A}$ & $\mathrm{A} / \mathrm{C}, \mathrm{G} / \mathrm{T}$ & 493 & 220 & $\mathrm{Y} / \mathrm{N}$ & $\mathrm{Y}$ & $\mathrm{Y}$ \\
\hline TS7 & $A>G$ & $\mathrm{G} / \mathrm{T}, \mathrm{A} / \mathrm{C}$ & 142 & 117 & $\mathrm{Y} / \mathrm{N}$ & $\mathrm{Y}$ & $\mathrm{Y}$ \\
\hline TS8 & $\mathrm{A}>\mathrm{G}$ & $\mathrm{G} / \mathrm{T}, \mathrm{A} / \mathrm{C}$ & 681 & 453 & $\mathrm{~N} / \mathrm{N}$ & $\mathrm{N}$ & $\mathrm{Y}$ \\
\hline \multicolumn{8}{|c|}{ Transversion } \\
\hline TV1 & $\mathrm{C}>\mathrm{A}$ & $\mathrm{A} / \mathrm{G}, \mathrm{C} / \mathrm{T}$ & 361 & 144 & $\mathrm{~N} / \mathrm{N}$ & $\mathrm{Y}$ & $\mathrm{Y}$ \\
\hline TV2 & $A>C$ & $\mathrm{C} / \mathrm{T}, \mathrm{A} / \mathrm{G}$ & 444 & 366 & $\mathrm{~N} / \mathrm{N}$ & $\mathrm{Y}$ & $\mathrm{Y}$ \\
\hline TV3 & $\mathrm{G}>\mathrm{T}$ & $\mathrm{T} / \mathrm{C}, \mathrm{G} / \mathrm{A}$ & 158 & 114 & $\mathrm{~N} / \mathrm{N}$ & $\mathrm{Y}$ & $\mathrm{Y}$ \\
\hline TV4 & $\mathrm{T}>\mathrm{G}$ & $\mathrm{G} / \mathrm{A}, \mathrm{T} / \mathrm{C}$ & 245 & 152 & $\mathrm{Y} / \mathrm{N}$ & $\mathrm{Y}$ & $\mathrm{Y}$ \\
\hline TV5 & $C>G$ & $\mathrm{G} / \mathrm{G}, \mathrm{C} / \mathrm{C}$ & 217 & 59 & $\mathrm{Y} / \mathrm{N}$ & $\mathrm{N}$ & $\mathrm{Y}$ \\
\hline TV6 & $C>G$ & $\mathrm{G} / \mathrm{G}, \mathrm{C} / \mathrm{C}$ & 379 & 169 & $\mathrm{~N} / \mathrm{Y}$ & $\mathrm{Y}$ & $\mathrm{Y}$ \\
\hline TV7 & $\mathrm{G}>\mathrm{C}$ & $\mathrm{C} / \mathrm{C}, \mathrm{G} / \mathrm{G}$ & 391 & 181 & $\mathrm{~N} / \mathrm{N}$ & $\mathrm{N}$ & $\mathrm{Y}$ \\
\hline TV8 & $\mathrm{A}>\mathrm{T}$ & $\mathrm{T} / \mathrm{T}, \mathrm{A} / \mathrm{A}$ & 276 & 143 & $\mathrm{Y} / \mathrm{N}$ & $\mathrm{Y}$ & $\mathrm{Y}$ \\
\hline TV9 & $\mathrm{T}>\mathrm{A}$ & $\mathrm{A} / \mathrm{A}, \mathrm{T} / \mathrm{T}$ & 212 & 97 & $\mathrm{~N} / \mathrm{N}$ & $\mathrm{N}$ & $\mathrm{Y}$ \\
\hline TV10 & $\mathrm{T}>\mathrm{A}$ & $\mathrm{A} / \mathrm{A}, \mathrm{T} / \mathrm{T}$ & 317 & 51 & $\mathrm{~N} / \mathrm{N}$ & $\mathrm{N}$ & $\mathrm{Y}$ \\
\hline \multicolumn{8}{|c|}{ Deletion or Insertion } \\
\hline D1 & 1bp del & 1bp bubble & 197 & 40 & $\mathrm{Y} / \mathrm{N}$ & $\mathrm{Y}$ & $\mathrm{Y}$ \\
\hline D2 & 2bp del & 2bp bubble & 267 & 231 & $\mathrm{~N} / \mathrm{Y}$ & $\mathrm{Y}$ & $\mathrm{Y}$ \\
\hline D3 & 5bp del & 5bp bubble & 296 & 63 & $\mathrm{Y} / \mathrm{Y}$ & $\mathrm{Y}$ & $\mathrm{Y}$ \\
\hline D4 & 18bp del & 18bp bubble & 583 & 227 & $\mathrm{~N} / \mathrm{Y}$ & $\mathrm{Y}$ & $\mathrm{Y}$ \\
\hline $\mathrm{I} 1$ & 1bp ins & 1bp bubble & 305 & 253 & $\mathrm{~N} / \mathrm{N}$ & $\mathrm{Y}$ & $\mathrm{Y}$ \\
\hline $\mathrm{I} 2$ & 2bp ins & 2bp bubble & 241 & 45 & $\mathrm{~N} / \mathrm{Y}$ & $\mathrm{Y}$ & $\mathrm{Y}$ \\
\hline I3 & 17bp ins & 17bp bubble & 301 & 189 & $\mathrm{Y} / \mathrm{Y}$ & $\mathrm{Y}$ & $\mathrm{Y}$ \\
\hline
\end{tabular}

Y, detected; N, not detected; In the SSCP/HA column, results of SSCP are indicated on the left side and HA results are indicated on the right side. 
Table 3. Sensitivity

\begin{tabular}{lccc}
\hline & SSCP/HA & T7EI & CEL \\
\hline Single base substitution & $7 / 18(39)$ & $11 / 18(61)$ & $18 / 18(100)$ \\
Transition & $3 / 8(38)$ & $5 / 8(63)$ & $8 / 8(100)$ \\
Transversion & $4 / 10(40)$ & $6 / 10(60)$ & $10 / 10(100)$ \\
Insertion + Deletion & $6 / 7(86)$ & $7 / 7(100)$ & $7 / 7(100)$ \\
All & $13 / 25(52)$ & $18 / 25(72)$ & $25 / 25(100)$ \\
\hline
\end{tabular}

Numbers in each box show detected / screened nucleotide changes (percentage) 


\section{FIGURE LEGENDS}

\section{Figure 1}

Comparing SSCP/HA and CEL enzyme mediated EMC. Band shift of SSCP/HA are indicated by white arrow heads, and cleaved bands by CEL are indicated by black arrow heads. Nucleotide changes indicated by index, TV1, TS6 and I2 are listed in Table 1. ss, single strand DNA; ds, double strand DNA. S, samples with mutation; C, wild type control.

\section{Figure 2}

Comparing gel and developing conditions of CEL enzyme mediated EMC. Cleaved bands by enzymes are indicated by black arrow heads. Index of nucleotide changes are according to Table 1 . PS, polyacrylamide gel with silver staining; PG, polyacrylamide gel with SYBR Green I staining; AE, agarose gel with ethidium bromide staining; AG, agarose gel with SYBR Green I staining. S, samples with mutation; C, wild type control.

\section{Figure 3}

Example of comparison of four enzymes for EMC. Cleaved band (indicated by black arrow heads) can be confirmed in CEL (SURVEYOR nuclease S) and T7 (T7 endonuclease I) but not in EV (Endonuclease V) and T4VII (T4 endonuclease VII). TS6 and D1 indicate DNA mutations described in Table 1. S, samples with mutation; C, wild type control.

\section{Figure 4}

Example comparing CEL nuclease and T7 endonuclease I mediated EMC. Cleaved bands by enzymes are indicated by black arrow heads and band shift by heteroduplex formation are indicated by white arrow heads. Index of nucleotide changes are according to Table 1 . S, samples with mutation; C, wild type control. 


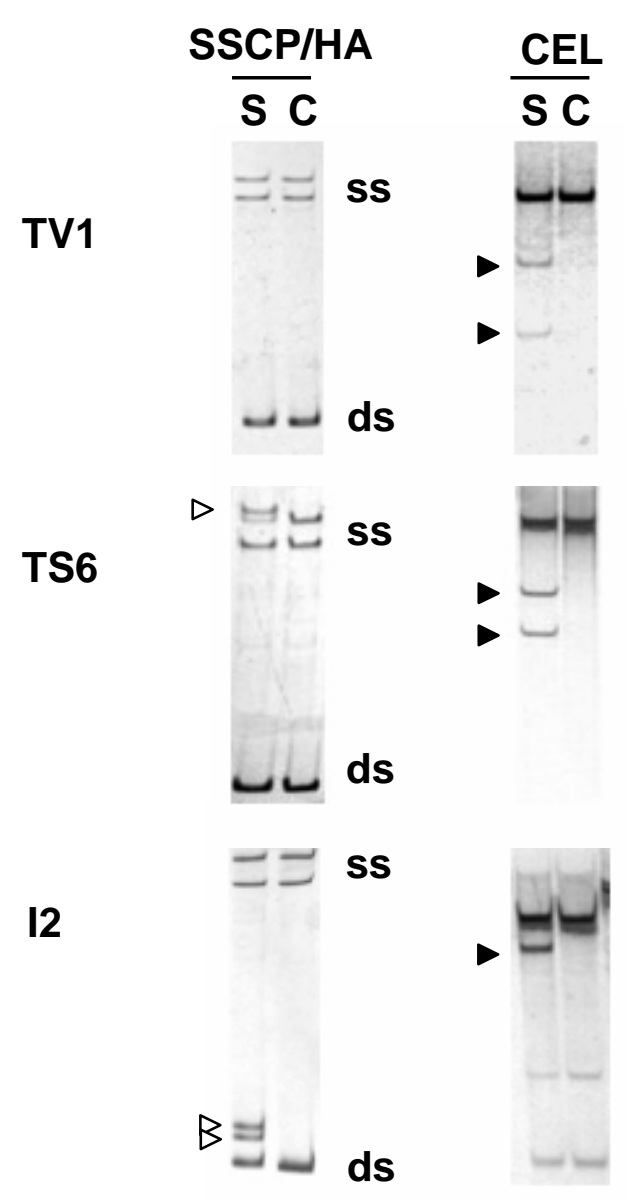




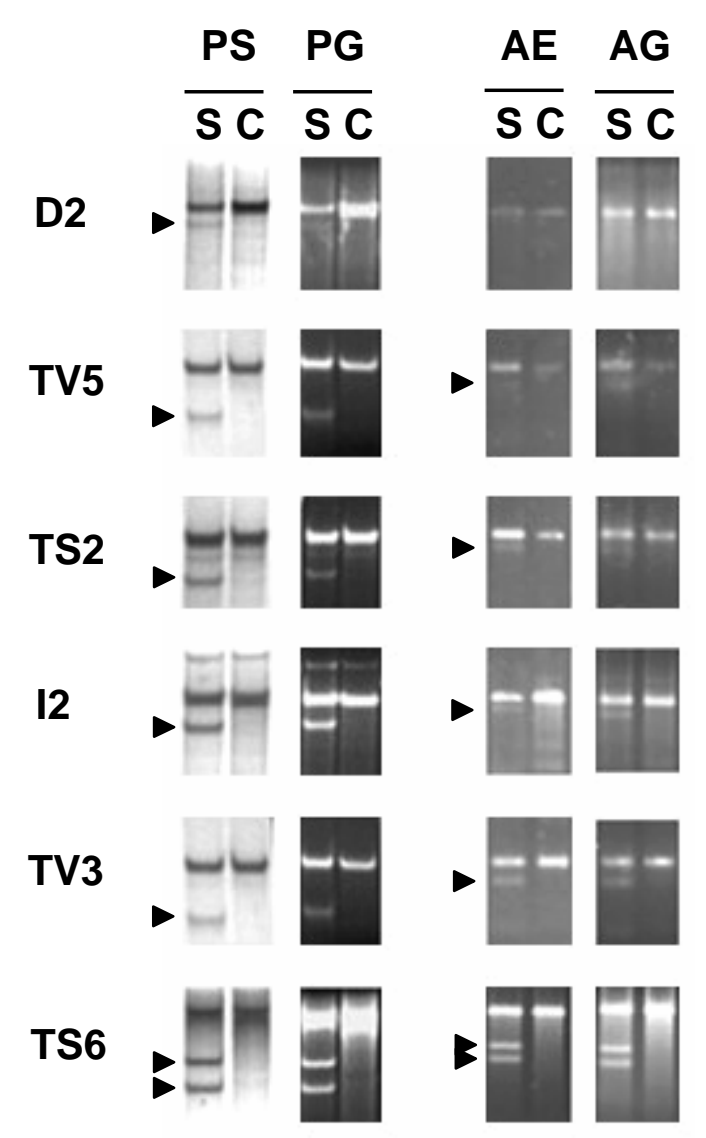




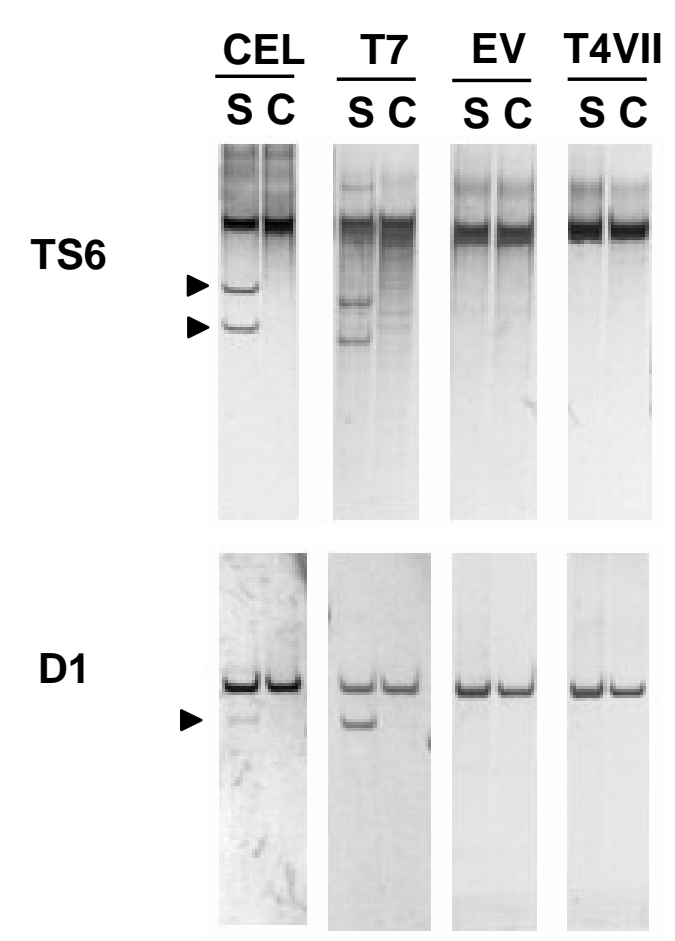



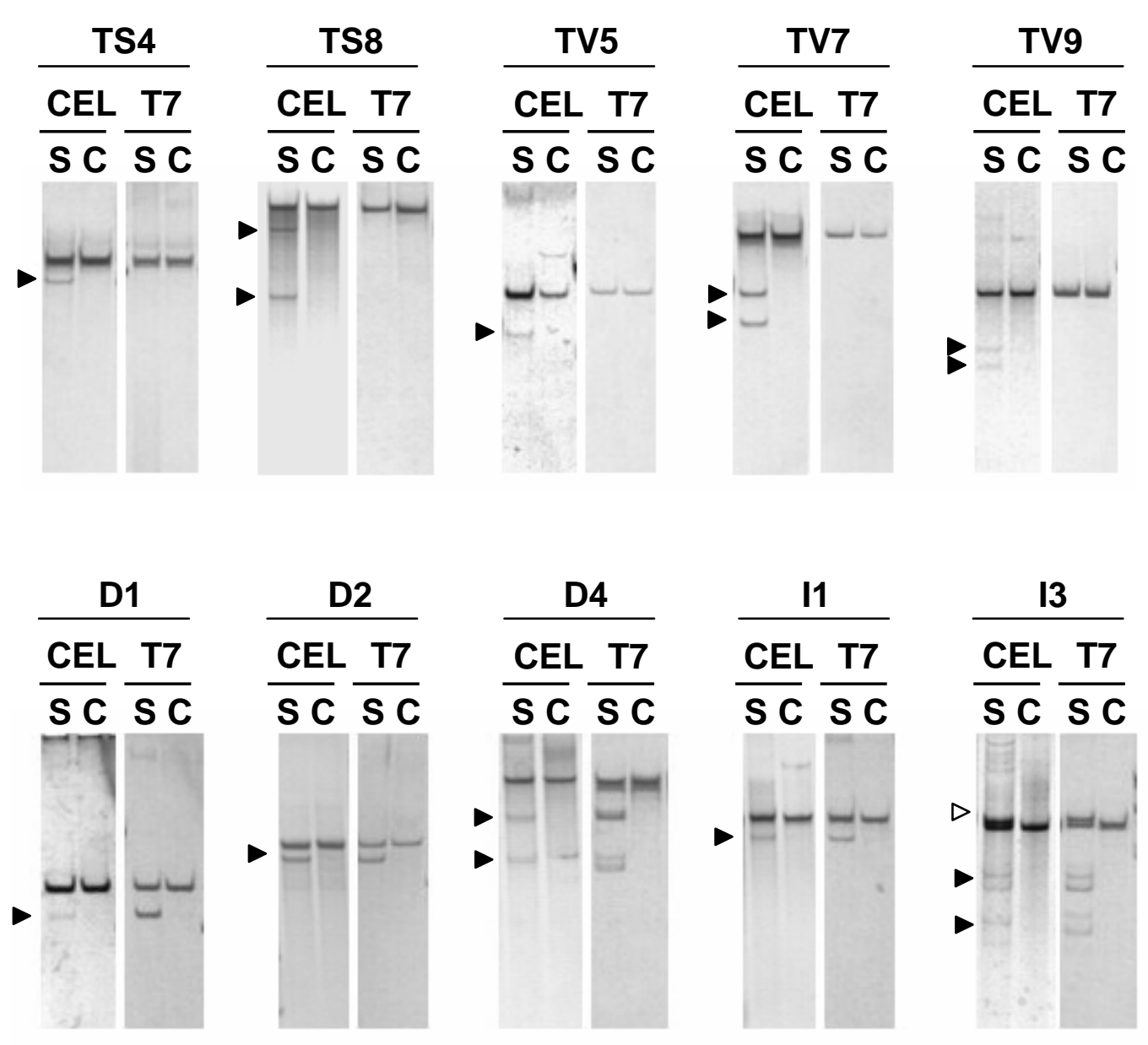